\title{
RANCANGAN BERKELANJUTAN RUMAH KARGO KONTAINER DENGAN SISTEM MODULAR DI JAKARTA UTARA
}

\author{
Albertus Prawata \\ Architecture Department, Faculty of Engineering, Binus University \\ Jl. K.H. Syahdan No. 9, Palmerah, Jakarta Barat 11480 \\ albertus_prawata@binus.ac.id
}

\begin{abstract}
Sustainable home design implements a sustainability system, in which the design can meet the needs of both current and future residents as well as the environment. Sustainable design is applied in order to save the environment and natural resources by minimizing its use. The house is designed as a whole by considering the management of water, waste and electricity. Social interactions and relationships between the environment and the residents nearby are also expected to be sustainable. Regarding to the needs of residents of the city which are diverse and dense, the house design implements a modular system, with the container material which suits the needs of its inhabitants. The modular system is objected to make easy the house improvement, assembility, and material reusage. Prefabricated process is also implemented, considering the transportation and construction. Thus the range of sustainable home design with modular systems in a dense region of North Jakarta meets the needs of the community and contributes to environment sustainability.
\end{abstract}

Keywords: sustainable home design, modular system, container material, environment sustainability

\begin{abstract}
ABSTRAK
Rancangan rumah berkelanjutan adalah rumah yang dirancang dengan menerapkan sistem keberlanjutan (sustainable design), di mana rancangan dapat memenuhi kebutuhan penghuninya pada saat ini dan penghuni serta lingkungannya di masa yang akan datang. Rancangan yang berkelanjutan diterapkan dengan tujuan untuk menghargai lingkungan dan sumber daya alam dengan meminimalkan penggunaannya. Rumah dirancang secara menyeluruh dengan mempertimbangkan faktor pengelolaan air, sampah dan listrik. Interaksi sosial dan hubungan antar penghuni terhadap lingkungan dan kawasan sekitarnya juga diharapkan dapat berkesinambungan. Dengan kebutuhan penghuni kota Jakarta yang beragam dan padat, rancangan rumah pun dirancang dengan menggunakan sistem modular, dengan material kontainer menyesuaikan kebutuhan penghuninya. Penggunaan sistem modular ini berfungsi agar rumah dapat berkembang, dapat dibongkar pasang dengan mudah dan materialnya dapat dipergunakan kembali. Proses prafabrikasi juga akan diterapkan, dengan mempertimbangkan akses transportasi dan konstruksinya di lapangan. Dengan demikian ragam rancangan rumah berkelanjutan dengan sistem modular di kawasan padat Jakarta Utara dapat memenuhi kebutuhan masyarakat dan juga berperan untuk menjaga kelestarian lingkungan.
\end{abstract}

Kata kunci: rancangan rumah berkelanjutan, sistem modular, rumah container, kelestarian lingkungan 


\section{PENDAHULUAN}

Pertumbuhan penduduk yang sangat pesat di kota-kota besar seperti Jakarta tentunya membuat perkembangan dan kebutuhan untuk hunian juga meningkat untuk memenuhi kebutuhan penduduknya. Berdasarkan data dari BADAN PUSAT STATISTIK DKI JAKARTA (2010), penduduk kota Jakarta telah mencapai 9,2 juta jiwa lebih, dengan luas wilayah $662,33 \mathrm{~km}^{2}$. Kepadatan penduduk Jakarta mencapai 13,9 ribu/ $/ \mathrm{km}^{2}$, sehingga menjadikan provinsi ini sebagai wilayah terpadat penduduknya di Indonesia. Namun, kepadatan penduduk ini tidak sebanding dengan luas lahan hunian kota Jakarta. Hal ini menyebabkan harga tanah di kota Jakarta semakin meningkat, sehingga penduduk dengan perekonomian rendah tidak dapat memiliki tanah secara legal. Hal ini mengakibatkan banyaknya permukiman kumuh illegal di penjuru kota Jakarta. Salah satunya terdapat di kelurahan Tanjung Priok khususnya di sekitar stasiun kereta api Tanjung Priok, Jakarta Utara.

Tanjung Priok merupakan letak pelabuhan utama yang menjadi pusat kegiatan ekspor dan impor di kota Jakarta. Pelabuhan ini merupakan salah satu gerbang perekonomian di Indonesia. Di daerah ini juga terdapat stasiun kereta api tua terbesar kedua setelah stasiun Gambir. Stasiun ini dibangun oleh Belanda pada tahun 1914 dan memiliki corak art deco. Stasiun ini menjadi peninggalan bangunan bersejarah dan menjadi bangunan yang dilindungi oleh pemerintah. Stasiun ini pernah ditutup dengan jangka waktu yang sangat lama, tetapi pada bulan Mei 2009, stasiun Tanjung Priok dibuka kembali dan diharapkan dapat berfungsi sebagai pendukung sistem transportasi publik di Jakarta.

Berbagai permasalahan yang didasari oleh kepadatan penduduk dialami di kelurahan Tanjung Priok. Peruntukan lahan di Tanjung Priok pada umumnya digunakan untuk industri dan juga sebagai tempat penyimpanan kontainer. Minimnya lahan yang ada menjadi penghalang bagi penduduk untuk memiliki sebuah ruang yang cukup dan sehat untuk dihuni. Di kelurahan Tanjung Priok, terdapat permukiman yang terdiri dari rumah permanen dan non permanen (Gambar 1), dan kawasan ini sangat padat dan kotor. Rumah-rumah tersebut pada umumya tidak memiliki pengudaraan dan pencahayaan alami yang baik. Rumah non-permanen juga banyak ditemui di sepanjang jalur kereta api menuju stasiun Tanjung Priok. Hal ini tentunya memberikan berbagai macam permasalahan baru seperti keselamatan dan citra negatif bagi kawasan tersebut. Solusi untuk menciptakan kawasan hunian yang baik di kelurahan Tanjung Priok harus segera direalisasikan agar tercipta suatu area permukiman yang aman, sehat dan mencukupi bagi kawasan tersebut. Hal tersebut nantinya juga akan memberikan dampak yang positif bagi kawasan Tanjung Priok itu sendiri, sehingga dapat memberikan citra dan contoh yang baik bagi konsep permukiman baru di kota Jakarta. Untuk itu, diperlukan pembangunan berkelanjutan di sektor permukiman. Pembangunan permukiman yang berkelanjutan diartikan sebagai upaya yang berkelanjutan untuk memperbaiki kondisi sosial, ekonomi dan kualitas lingkungan tempat hidup dan bekerja semua orang. Sehingga dalam melaksanakan pembangunan permukiman yang berkelanjutan sangat penting untuk mempertimbangkan permukiman yang berwawasan lingkungan (Aulia. 2005).

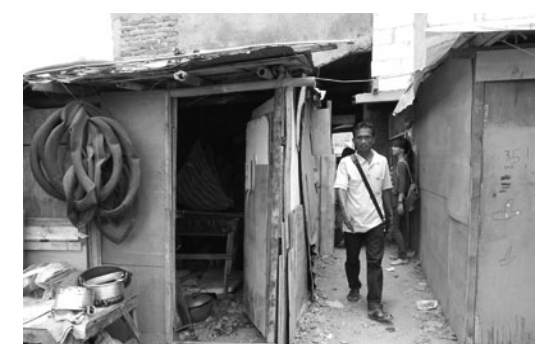

Gambar 1. Salah satu rumah non-permanen di kelurahan Tanjung Priok (sumber: Albertus Prawata). 


\section{METODE}

Paper ini disusun dengan pendekatan deskriptif berdasarkan pengamatan penulis di lapangan, yaitu di kawasan Tanjung Priok, Jakarta Utara. Selain itu dilakukan pula tinjauan pustaka untuk memperkaya informasi yang berkaitan dengan pembahasan masalah utama.

\section{HASIL DAN PEMBAHASAN}

Menurut Desyana (2008), lebih dari 5000 kontainer masuk pelabuhan Tanjung Priok setiap harinya, dan dengan adanya krisis global yang melanda Eropa dan Amerika Serikat menyebabkan lalu lintas kontainer (ekspor dan impor) mengalami penurunan sebesar 40 persen. Ini berarti, banyak kontainer yang tidak digunakan dan hanya berdiam di gudang maupun area penyimpanan kontainer di pelabuhan.

Penggunaan kontainer kapal sebagai material utama bangunan sudah sering digunakan dan diaplikasikan. Material kontainer kapal ini banyak yang digunakan untuk rumah tinggal, galeri, sekolah sampai dengan musium. Hal ini menunjukan bahwa material kontainer menjadi material yang dapat digunakan ulang fungsinya sebagai material utama bangunan, sehingga dapat menekan dan menghemat biaya pembangunan. Hal ini juga menunjukan salah satu upaya para desainer dan arsitek untuk melakukan upaya penghematan sumber daya yang tidak terbarukan. Kontainer kapal ini merupakan material yang sangat kuat, dan sudah teruji dari segala kondisi cuaca. Kontainer kapal (Dry cargo containers), merupakan kontainer yang paling sering digunakan, terdiri dari 2 jenis yang memiliki beda ukuran. 20 feet cargo container, yang memiliki panjang 6,058m, lebar 2,438m dan tinggi 2,591m. Dan 40 feet cargo container, yang memiliki panjang 12,192m, lebar 2,438m dan tinggi 2,591m (Nurkamdani. 2010).

Kontainer-kontainer kapal yang banyak ditemukan di sekitar kawasan Tanjung Priok menjadikannya material yang baik untuk digunakan ulang sebagai rumah tinggal bagi para penduduk sekitar di kelurahan Tanjung Priok. Material kontainer tersebut tentunya tidak bisa segera dipakai secara langsung sebagai rumah tinggal. Yang bisa dilakukan adalah, merancang ulang kontainer tersebut dengan dasar struktur kontainer yang sudah tetap (Gambar 2).

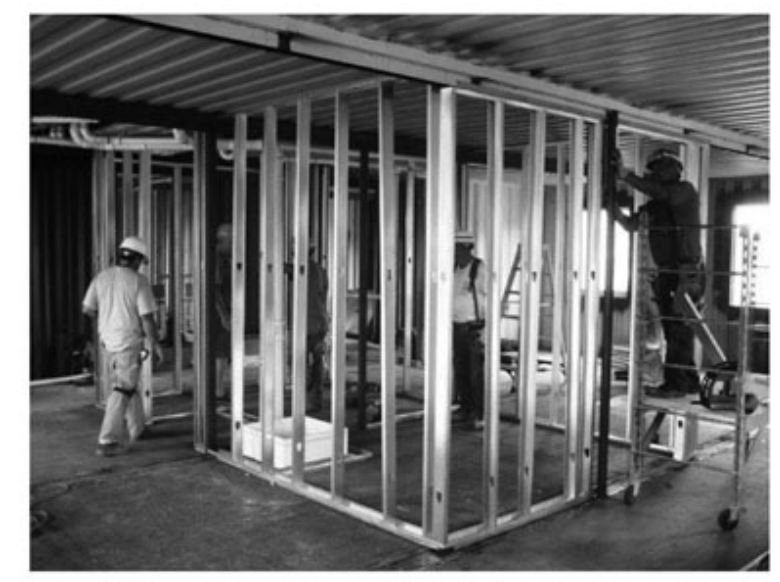

Gambar 2. Interior kontainer kapal yang dirancang ulang dan ditambahkan strukturnya untuk memenuhi kebutuhan rumah tinggal (sumber: Hart, 2011). 
Para pengembang dan pihak-pihak lain yang aktif terlibat dalam pengembangan kota seharusnya dapat memanfaatkan hal ini, dan menjadikan rangka modular kontainer sebagai struktur utama untuk pembuatan rumah tinggal yang ramah lingkungan, khususnya untuk kelurahan Tanjung Priok.

Ukuran modul kontainer sebagai material utama untuk dirancang ulang menjadi rumah tinggal modular yang berkelanjutan di kawasan Tanjung Priok, akan semakin memudahkan konstruksi dan juga perancangan rumah-rumah tinggal baru bagi penduduk sekitar secara menyeluruh. Bentuk modular yang dimiliki oleh kontainer tentunya akan memudahkan pemindahannya dari satu tempat ke tempat lainnya. Sehingga pengaplikasian dan pemanfaat rumah tinggal sistem modular dapat digunakan diseluruh penjuru kota. Letak lokasi (site) di Tanjung Priok yang berdekatan dengan jalur kereta api menjadikannya sebagai hal yang positif. Dengan ukuran standar internasional, pemindahan rangka dan struktur modular yang ada, rumah-rumah tersebut dapat dibuat di pabrik (pre-fabrikasi), lalu bisa dipindahkan dengan kereta api maupun truk.

Dengan ukuran modul yang ada, yaitu 6,058m x 2,438m x 2,591m dan 12,192m x 2,438m x 2,591m), dapat diatur konfigurasinya sesuai dengan kapasitas dan kebutuhan penghuninya. Dalam konteks perancangan rumah berkelanjutan dengan sistem modular di kelurahan Tanjung Priok, penghuni rumah ini bervariasi dari keluarga dengan dua anak (Gambar 3) sampai empat anak (Gambar 4) ditambah dengan sanak keluarga yang lain (Gambar 5), sampai dengan penghuni yang belum berkeluarga.
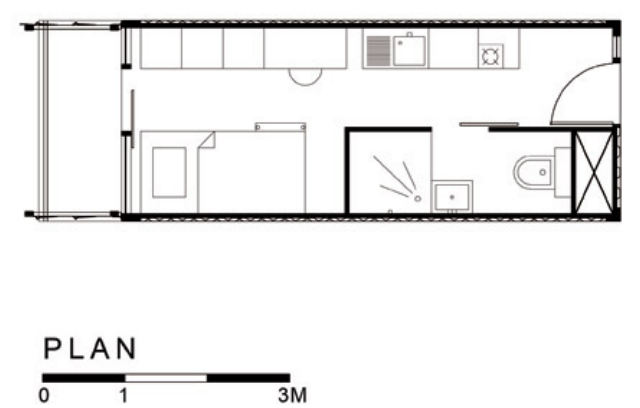

Gambar 3. Modul 1 (6,058m x 2,438m x 2,591m), dapat digunakan untuk jumlah penghuni yang kecil antara 1sampai dengan 2 orang (Sumber: Albertus Prawata).

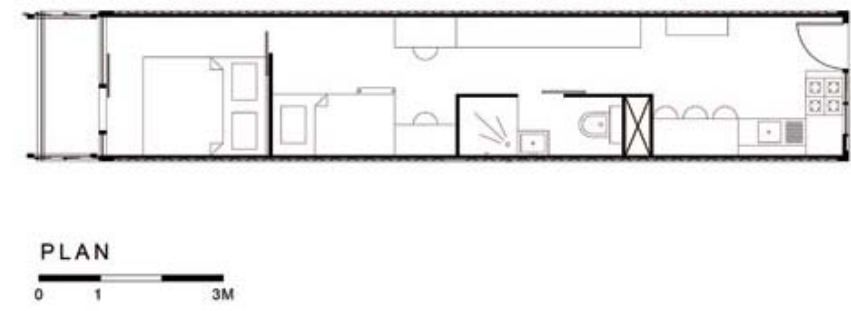

Gambar 4. Modul 2 (12,192m x 2,438m x 2,591m), dapat digunakan untuk anggota keluarga yang terdiri dari 4 orang

(Sumber: Albertus Prawata). 

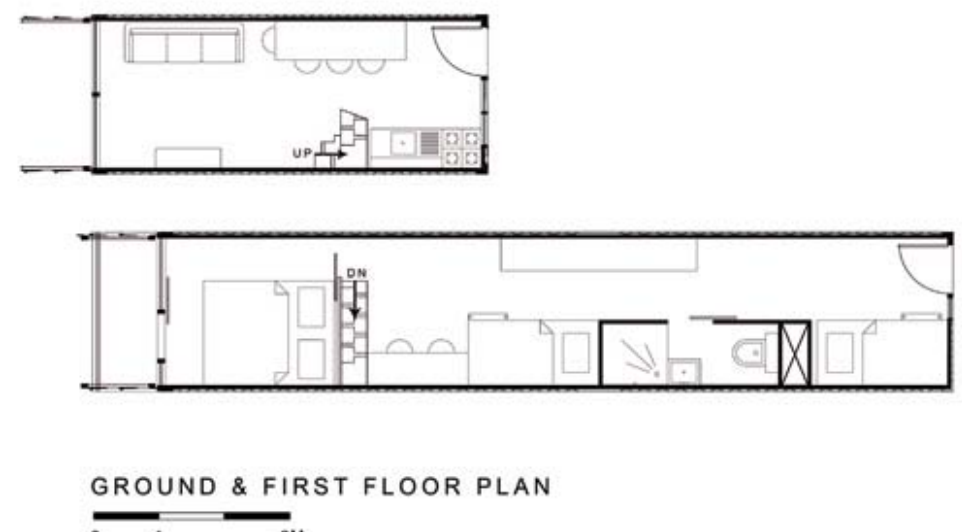

Gambar 5. Penggabungan modul 1 dan 2, dapat digunakan untuk anggota keluarga yang terdiri dari 4-6 orang

(Sumber: Albertus Prawata).

Modul-modul tersebut dapat menjadi unit-unit rumah secara terpisah maupun dapat diatur sedemikian rupa dan dibuat unit-unit yang tersusun menjadi sebuah rumah susun bertingkat (Gambar 6), sehingga dapat menghemat ruang yang ada dengan membangun dan menambahkan secara vertikal.
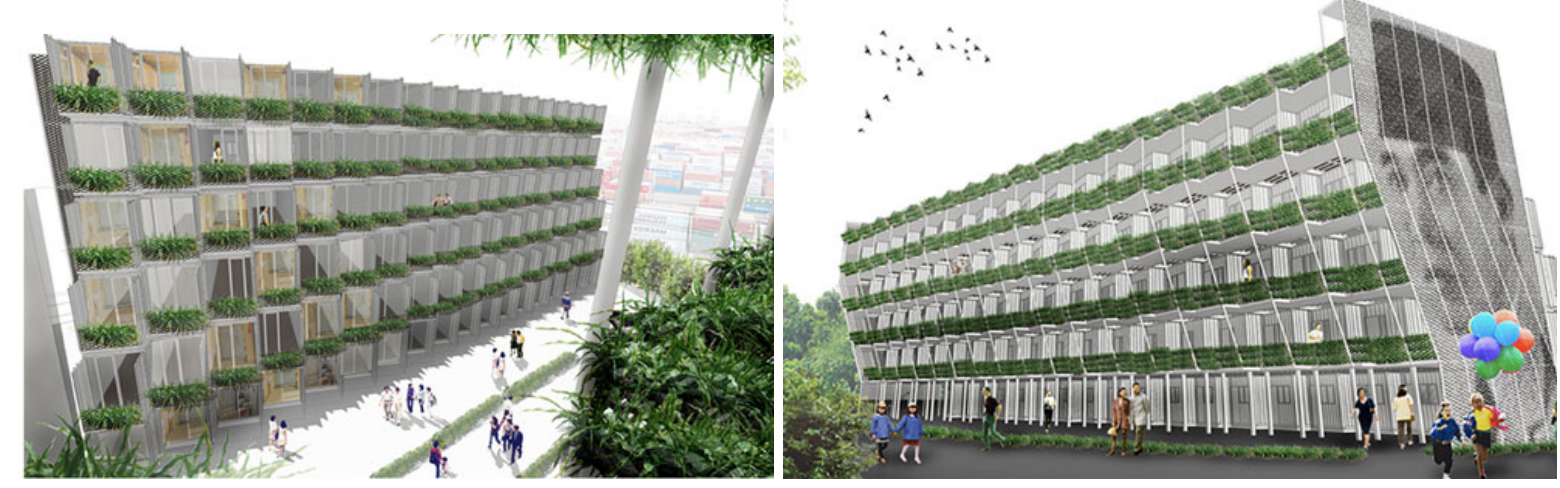

Gambar 6. Modul 1 dan 2 dapat disusun bertingkat (vertikal) dan membetuk sebuah hunian yang dapat menampung jumlah orang yang lebih banyak (sumber: Albertus Prawata).

Pada bagian atap rumah atau unit modul-modul dapat dibuat atap rumput (roof garden, Gambar 7). Selain itu pada bagian koridor dan balkon dapat dibuat vertical planting, ataupun dengan meletakan tanaman-tanaman di dalam pot yang tentunya dapat berguna untuk penurunan suhu maupun dapat menjadi penyedia sumber pangan. 


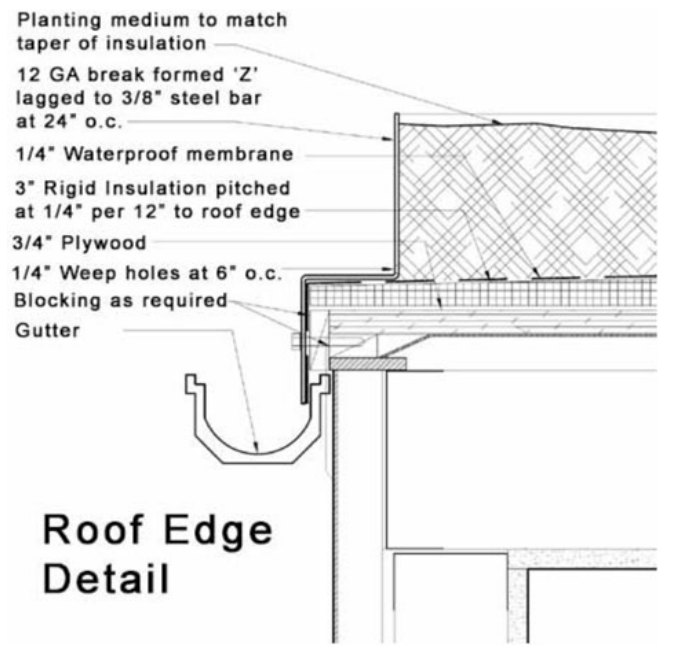

Gambar 7. Detail potongan atap yang dapat dibuat roof garden (sumber: Resendetial Shipping Container Primer, 2011).

Penerapan sistem rainwater harvesting juga bisa diterapkan pada unit modul rumah tinggal ini, dengan membuat sistem dan jalur penampungan air hujan yang langsung dapat dilarikan ke penampungan air hujan. Air hujan ini dapat bermanfaat untuk penyiraman toilet, tanaman sampai membersihkan dan mencuci kendaraan pribadi. Dengan menampung air hujan untuk digunakan ulang tentu akan mengurangi beban penggunaan air tanah, dan mencegah banjir. Elemen desain lainnya yang bisa diterapkan adalah penggunaan sistem biogas sebagai energi alternatif yang mendaur ulang limbah organik dan juga limbah manusia dan binatang, untuk diubah menjadi gas, dan dapat menggantikan energi gas pada umumnya untuk kegiatan memasak. Pembuatan lubang-lubang biopori di daerah sekitar rumah dan permukiman juga bisa diterapkan, sehingga bisa mencegah banjir, dan bisa didapatkan pupuk dari sampah organik dan bisa digunakan untuk membantu menyuburkan tanaman lain.

\section{PENUTUP}

Penggunaan struktur material kontainer kapal sebagai material yang didaur ulang untuk dijadikan suatu modul unit rumah tinggal, merupakan salah satu cara yang baik dan positif dalam upaya mereduksi pemakaian sumber daya alam yang tidak terbarukan. Dengan sistem modular tersebut, ruang-ruang untuk rumah tinggal dapat dibentuk sedemikian rupa untuk memenuhi kebutuhan penghuninya. Sistem modular juga akan sangat memudahkan proses konstruksi dan pengaplikasian rumah tinggal modular ini. Dengan ukuran modul yang dapat dengan mudah dipindahpindahkan baik dengan kereta api maupun dengan truk, unit-unit modul rumah ini dapat dibuat di suatu lokasi (pre-fabrikasi), dan dipindahkan ke daerah yang memiliki permasalahan seperti kepadatan penduduk. Lokasi di kelurahan Tanjung Priok merupakan tempat yang ideal untuk proyek ini karena berdekatan dengan sistem transportasi (kereta api) yang dengan mudah dapat mendistribusikan rumah tinggal modular, dan juga tersedianya material kontainer sebagai rangka modul utamanya.

Berbagai upaya penghematan untuk membuat bangunan hunian baru dengan sistem modular di kelurahan Tanjung Priok yang cenderung kumuh dan padat, tentunya akan memberikan citra yang baik bagi kawasan tersebut. Penyebaran penduduk juga bisa ditekan, sehingga angka perjalanan untuk menuju tempat kerja bisa menurun karena tersedianya tempat hunian yang mencukupi, sehat dan dapat mendukung aktifitas penghuninya. Sarana transportasi umum yang memadai dan menyebar ke seluruh 
jaringan transportasi publik di Jakarta juga menjadikan Tanjung Priok memiliki nilai lebih. Pembuatan dan pengembangan rumah tinggal dengan sistem modular ini diharapkan juga dapat diaplikasikan di seluruh penjuru kota, sehingga upaya penghematan dapat dilakukan secara menyeluruh.

\section{DAFTAR PUSTAKA}

Aulia, Dwira N. (2005). Permukiman yang berwawasan lingkungan tinjauan. Jurnal Sistem Teknik Industri, 6(4).

Badan Pusat Statistik DKI Jakarta. (2010). Jakarta Dalam Angka 2010 (edisi pertama). Jakarta: Badan Pusat Statistik DKI Jakarta.

Desyana, Cornila. (2008). Pengelolaan peti kemas tanjung priok buruk. Tempo Interaktif. Diakses 14 April 2012 dari http://www.tempointeractive.com/hg/ekbis/2008/09/12/brk,20080912135073,id.html.

Hart, Kelly. (2011). Building with shipping containers. Green Home Building. Diakses 13 April 2012 dari http://www.greenhomebuilding.com/articles/containers.htm.

Nurkamdani, Andri Rizky. (2010). Rumah Container Bertingkat Dengan Pendekatan Green Metabolist.

Resedential Shipping Container Primer. (2011). Container Home Green Roof and Framing. Resedential Shipping Container Primer. Diakses 14 April 2012 dari http://residentialshippingcontainerprimer.com/Green\%20Roof.

Tugas Akhir tidak diterbitkan. Program Studi Arsitektur Fakultas Teknik Universitas Sebelas Maret, Surakarta. 